\title{
EPISTAXIS- CONTRIBUTORY AND ASSOCIATED FACTORS AND MANAGEMENT
}

\author{
K. Sreenivas ${ }^{1}$, P. Achyuth ${ }^{2}$
}

${ }_{1}^{1}$ Assistant Professor, Department of ENT, Osmania Medical College/Government ENT Hospital.

${ }^{2}$ Senior Resident, Department of ENT, Osmania Medical College/Government ENT Hospital.

\section{BACKGROUND}

ABSTRACT

Epistaxis is the most common otolaryngologic emergency and affects up to $60 \%$ of the population in their lifetime, and $6 \%$ require medical attention. The variability of severity can range from outpatient management to admission to the intensive care unit from conservative treatment. The management of a patient with epistaxis ranges from the replacement of blood loss, direct visuali sation and cautery, nasal packing and surgical (endoscopic or external) and embolisation.

The objective of this study is to measure the contributory and associated factors for patients presenting to the ENT emergency with Epistaxis. It is considered as the second most common condition, in which patient presents to ER. In the present study, a total of 42 patients presenting with epistaxis to the ENT Casualty at Govt. ENT Hospital has been studied retrospectively.

The aim of this study is to study the factors associated and contributing to the Epistaxis.

\section{MATERIALS AND METHODS}

This is a retrospective descriptive study of Epistaxis cases, which presented to ENT casualty from January 2015 to December 2015. The study included a total of 42 cases above 7 years and below 80 years. Consent was taken for the study. The cases were evaluated with appropriate investigations. Diagnostic Endoscopic Examination was done whenever required.

\section{RESULTS}

Out of 42, 31 patients were males and 11 were females with M: F ratio of 2.81: 1, M (73.28\%), F (26.1\%). Min Blood pressure of the patient at presentation was 90 systolic/ 60 diastolic mmHg, max BP was 170 systolic/ 110 diastolic mmHg. With mean BP being 126 systolic/ 82 diastolic mmHg, haemoglobin on admission was min: 6 gm $\%$ and max: 15.3 gm $\%$ with mean Hb\% being $11.52 \%$. 7 patients (16.66\%) had history of alcohol consumption, 6 (40\%) patients were known hypertensives, 28 (66.67\%) patients were managed conservatively with bilateral anterior nasal packing with BIPP, 9 (21.4\%) were managed with postnasal packing and ANP, $3(7.1 \%)$ were managed with silver nitrate cautery and $2(4.7 \%)$ with bipolar cautery under local anaesthesia.

\section{CONCLUSION}

Epistaxis is more common in elderly age group, B+ve blood group, most commonly managed with Bilateral Anterior Nasal Packing, most common reason being hypertension.

\section{KEYWORDS}

Epistaxis, BIPP, ANP, Nasal Packing.

HOW TO CITE THIS ARTICLE: Sreenivas K, Achyuth P. Epistaxis- contributory and associated factors and management. J. Evolution Med. Dent. Sci. 2018;7(10):1171-1173, DOI: 10.14260/jemds/2018/267

\section{BACKGROUND}

Epistaxis is the most common otolaryngologic emergency and affects up to $60 \%$ of the population in their lifetime, and $6 \%$ require medical attention. ${ }^{1}$ The management of epistaxis is one of the most commonly encountered clinical scenarios by the practicing otolaryngologist.

The variability of severity can range from outpatient management to admission to the intensive care unit from conservative treatment with nasal pressure to the necessity of surgical ligation in the operating room, and from a quick and satisfying outcome to a frustrating chronic problem or even life-threatening situation. Decisions about the optimum therapeutic intervention and timing are often made on an adhoc basis, and most units do not have a protocol (Systematic

'Financial or Other Competing Interest': None.

Submission 24-01-2018, Peer Review 17-02-2018,

Acceptance 23-02-2018, Published 05-03-2018.

Corresponding Author:

Dr. K. Sreenivas,

Flat No. 401, AGR Towers,

Saleemnagar Colony,

Malakpet, Hyderabad-36.

E-mail: sreenivaskosoori@gmail.com

DOI: $10.14260 /$ jemds $/ 2018 / 267$

\section{(c) $(i) \$$}

algorithm) for the management of epistaxis, ${ }^{2}$ despite some recently published guidelines and reviews.3,4,5 The management of a patient with epistaxis ranges from the replacement of blood loss, direct visualisation and cautery, nasal packing and surgical (Endoscopic or external) and embolisation.

\section{MATERIALS AND METHODS}

This is a retrospective descriptive study of Epistaxis cases, which presented to ENT casualty from January 2015 to December 2015. The study included a total of 42 cases above 7 years and below 80 years. Consent was taken for the study. The cases were evaluated with appropriate investigations. Diagnostic Endoscopic Examination was done whenever required.

\section{Objective}

To measure the contributory and associated factors for patients presenting to the ENT emergency with Epistaxis. It is considered as the second most common condition with which patients present to ER.

In the present study, a total of 42 patients presenting with epistaxis to the ENT Casualty at Govt. ENT Hospital has been 
studied retrospectively. The aim of this study is to study the factors associated and contributing to the Epistaxis.

\section{Study Setting}

This retrospective study on Epistaxis was conducted in the Department of ENT, Govt. ENT Hospital, Koti, for a period of one year from January 2015 - December 2015.

\section{Inclusion Criterion}

1. All patients above the age of 7 years and below 80 years.

2. Active nasal bleeding, anterior/ posterior; unilateral / bilateral.

3. No prior treatment anywhere outside in the form of nasal packing/ cautery/ embolisation.

\section{Exclusion Criterion}

1. Non-cooperative patients for evaluation and treatment.

2. Patients refusing to give consent.

3. Post-operative (FESS, ESS for benign or malignant tumours, maxillofacial trauma).

\section{RESULTS}

We present a series of 42 patients who presented to the ENT casualty with Epistaxis from January 2015 till December 2015.

Out of 42, 31 patients were males and 11 were females with M: F ratio of 2.81: 1, M (73.28\%) and F (26.1\%).

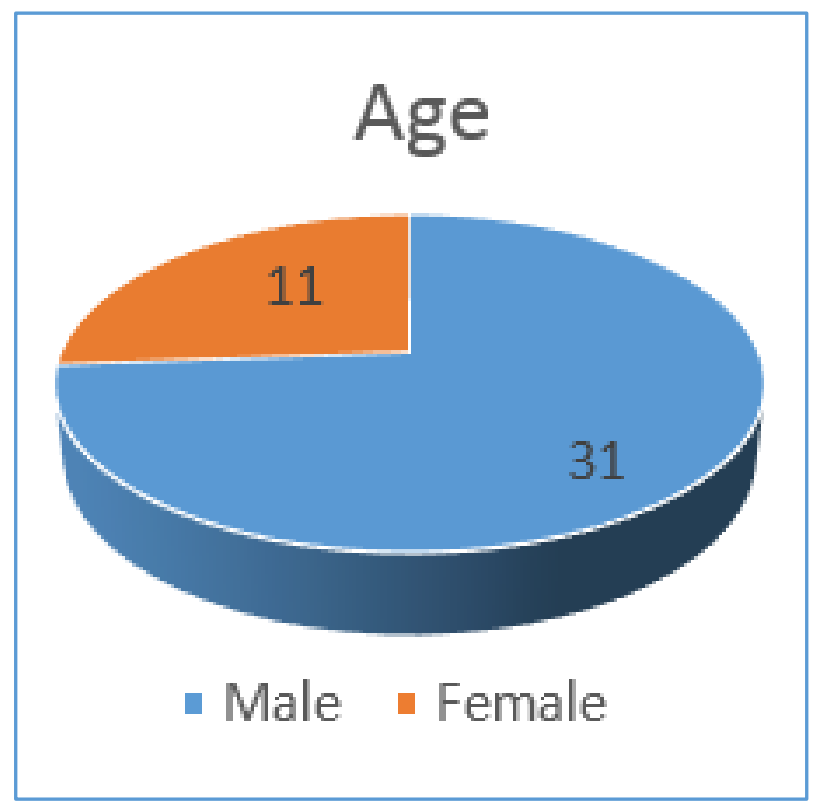

Minimum age of presentation being 11 years and max age of presentation is 75 years with average age of presentation being 44 years.

Min Blood Pressure of the patient at presentation is 90 systolic/ 60 diastolic mmHg, max BP is 170 systolic/ 110 diastolic mmHg. With mean BP being 126 systolic/ 82 diastolic $\mathrm{mmHg}$.

Haemoglobin on admission was min: 6 gm\% and max: $15.3 \mathrm{gm} \%$ with mean $\mathrm{Hb} \%$ being $11.52 \%$.

Blood group of 26 (61.9\%) patients is B+ve, 12 (28.5\%) patients is $0+v e$ with $B$-ve in 2, 0 -vein $1, A+v e$ in 1 in each of the remaining 4 patients.

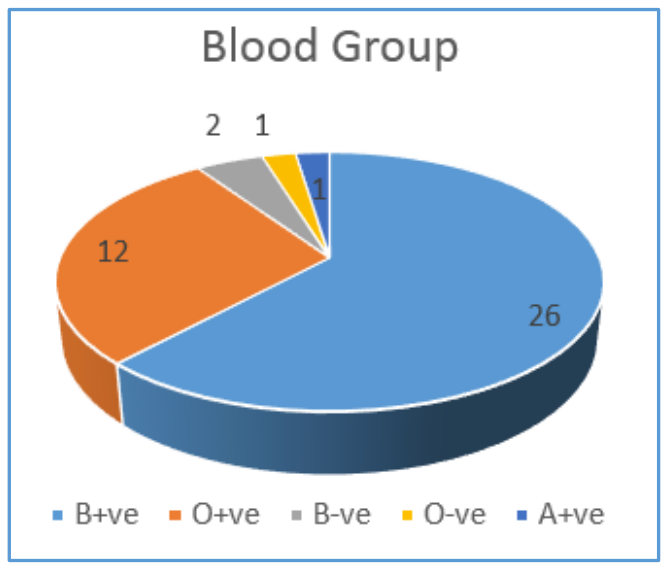

7 patients (16.66\%) had history of alcohol consumption, $6(40 \%)$ patients were known hypertensives on regular antihypertensive medication.

$13(30.95 \%)$ patients had history of coronary artery disease and were on antiplatelet aggregation treatment with clopidogrel (oral form).

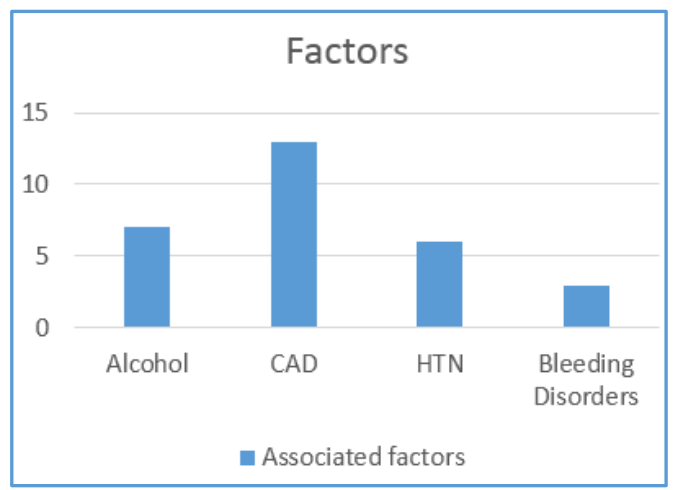

$16(38.8 \%)$ patients had left nostril bleeding, 8 had right nasal bleeding (19.04\%) and the remaining 18 (42.8\%) patients had bilateral nasal bleeding. $3(7.1 \%)$ patient had history of bleeding diathesis. $28(66.67 \%)$ patients were managed conservatively with bilateral anterior nasal packing with BIPP, $9(21.4 \%)$ were managed with post nasal packing and ANP, $3(7.1 \%)$ were managed with silver nitrate cautery and $2(4.7 \%)$ with bipolar cautery under local anaesthesia.

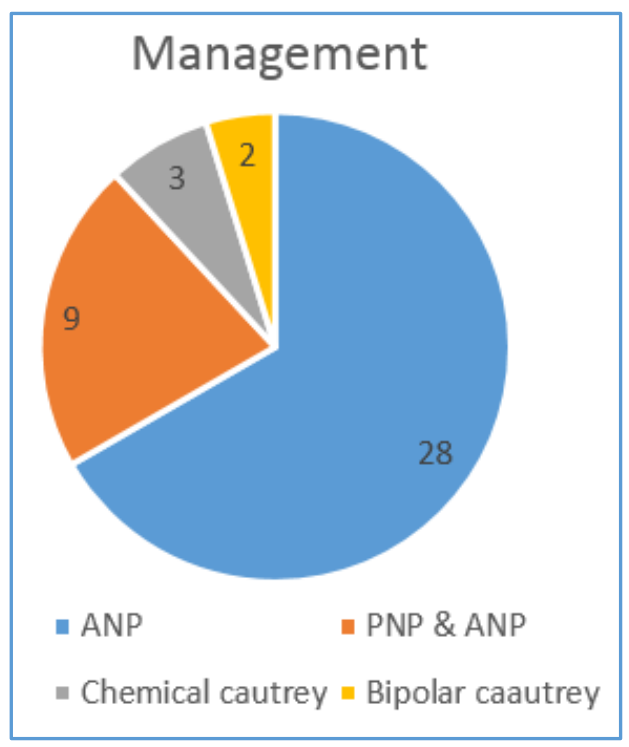


$6(14.2 \%)$ patients required repacking after the initial pack removal. 13 patients were discharged after 2 days of conservative management.

\section{DISCUSSION}

Epistaxis is defined as bleeding from the nose. Traditionally, epistaxis has been classified on the basis of presumed aetiology and publications include long list of factors thought to cause the condition. There is a pronounced bimodal distribution in the age of onset of epistaxis.

The condition is common in childhood, becomes less common in early adult life and then peaks in the sixth decade. Between 70 and 80 percent of all cases of epistaxis are idiopathic, spontaneous bleeds without any proven precipitant or causal factor. This type of bleeding can be classified as primary epistaxis. A small proportion are due to a clear and definite cause such as trauma, surgery or anticoagulant overdose and can be classified as secondary epistaxis. Recently, McGarry6 separated anterior epistaxis bleeding from a source anterior to the plane of the piriform aperture from posterior epistaxis bleeding posterior to this plane.

\section{Anterior Epistaxis}

Bleeding from a source anterior to the plane of the piriform aperture. This includes bleeding from the anterior septum and rare bleeds from the vestibular skin and mucocutaneous junction.

\section{Posterior Epistaxis}

Bleeding from a vessel situated posterior to the piriform aperture. This allows further subdivision into lateral wall, septal and nasal floor bleeding. Recurrent primary epistaxis tends to be minor, non-life-threatening and often easily managed whereas acute, severe epistaxis is usually a onetime event resulting in hospitalisation and carrying a high morbidity.

By definition the aetiology of primary epistaxis is unknown, but there are clear suggestions that systemic factors may be important. The frequency of admission is greatest in the autumn and winter months. A chronobiological rhythm is also observed at the circadian level, where onset of bleeding and hospital admission show a biphasic pattern with peaks in the morning and late evening.

Adult pattern epistaxis is associated with the use of nonsteroidal anti-inflammatory drugs (NSAID). The action of NSAIDs is mediated via an antiplatelet aggregation effect due to altered platelet membrane physiology.

Epistaxis patients are more likely to consume alcohol than matched control patients and are more likely to have consumed alcohol within 24 hours of hospital admission than other emergency admissions. Hypertension has long been considered a cause of epistaxis. However, a number of large studies have failed to show a causal relationship between hypertension and epistaxis.

Attempts to correlate epistaxis with secondary effects of hypertension or with the severity of hypertension have proved inconclusive.

The management of a patient with epistaxis ranges from the replacement of blood loss, direct visualisation and cautery, nasal packing and surgical (endoscopic or external) embolisation. A reduction in blood pressure is often a late sign, particularly in young people who can maintain blood pressure until circulatory volume becomes critical. A transfusion threshold of $9 \mathrm{~g} / \mathrm{dL}$ has been advocated, because this has been shown to improve outcome. Hot water irrigation as a non-invasive treatment for posterior epistaxis has received some renewed attention.7,8,9,10

\section{CONCLUSION}

Most of the cases could be managed satisfactorily using BIPP Packing through ANP. Posterior epistaxis required PNP. Adequate hydration and timely transfusion of blood elements led to treatment without any grave complications or squeal.

\section{REFERENCES}

[1] Small M, Murray JA, Maran AG. A study of patients with epistaxis requiring admission to hospital. Health Bull (Edinb) 1982;40(1):20-9.

[2] Pope LE, Hobbs CG. Epistaxis: an update on current management. Postgrad Med J 2005;81(955):309-14.

[3] Daudia A, Jaiswal V, Jones NS. Guidelines for the management of idiopathic epistaxis in adults: how we do it. Clin Otolaryngol 2008;33(6):618-20.

[4] Spielmann PM, Barnes ML, White PS. Controversies in the specialist management of adult epistaxis: an evidence-based review. Clin Otolaryngol 2012;37(5):382-9.

[5] McGarry GW. Epistaxis. In: Gleeson M. (eds). ScottBrown's otorhinolaryngology head \& neck surgery. Vol 2. $7^{\text {th }}$ edn. Chapter 126. London, Hodder-Arnold, 2008:1596-608.

[6] McGarry GW. Nasal endoscope in posterior epistaxis: a preliminary evaluation. J Laryngol Otol 1991;105(6):428-31.

[7] Schlegel-Wagner C, Siekmann U, Linder T. Noninvasive treatment of intractable posterior epistaxis with hot-water irrigation. Rhinology 2006;44(1):90-3.

[8] Novoa E, Schlegel-Wagner C. Hot water irrigation as treatment for intractable posterior epistaxis in an outpatient setting. J Laryngol Otol 2012;126(1):58-60.

[9] Guice NL. Hot water in epistaxis. Mississippi Valley Medical Monthly 1884:3-4.

[10] Stangerup SE, Dommerby H, Siim C, et al. New modification of hot water irrigation in the treatment of posterior epistaxis. Arch Otolaryngol Head Neck Surg 1999;125(6):686-90. 